\title{
The Effect of Graphene/Ag Nanoparticles Addition on the Performances of Organic Solar Cells
}

\author{
Cheng Fang Ou \\ Department of Chemical and Materials Engineering, National Chin-Yi University of Technology, Taiwan \\ Email: oucf@ncut.edu.tw
}

Received 20 October 2015; accepted 10 December 2015; published 17 December 2015

\begin{abstract}
Graphene/Ag nanoparticles (GAg) were fabricated via a facile method, employing graphite oxide as a precursor of graphene sheet (GNS), $\mathrm{AgNO}_{3}$ as a precursor of $\mathrm{Ag}$ nanoparticles, and sodium citrate as a reducing and stabilizing agent. We synthesized three kinds of GAg as GAg-1, GAg-2 and GAg-3. We introduced high electron mobility GAg into the active layer of polymer solar cell. The cell structure was ITO/PEDOT:PSS/P3HT:PCBM:GAg/Ca/Al. The weight ratio of P3HT:PCBM:GAg of active layer is 1:1:0.01. We study the effect of GAg addition on the photovoltaic performance. We use the UV-Vis, SPM, FE-SEM and solar simulator to measure the absorbance, roughness, surface morphology, and power conversion efficiency (PCE), respectively. From these results, we found that the fill factor (FF) and PCE of the cells with GNS or GAg are always higher than those of cell without GNS or GAg. The cell with GAg-2 had the highest short circuit current density $\left(\mathrm{J}_{s c}\right)$ of 8.56 $\mathrm{mA} / \mathrm{cm}^{2}$, an increase of $20.2 \%$, the highest fill factor (FF) of 0.56 , an increase of $14.3 \%$ and the highest PCE of $2.78 \%$. This is a $24.7 \%$ increase in efficiency compared to the cell without GNS or GAg. These improvements were due to the high carrier mobility of grapheme.
\end{abstract}

\section{Keywords}

Graphene, Nanoparticle, Polymer Solar Cell, Power Conversion Efficiency

\section{Introduction}

The solution-process able polymer bulk hetero junction (BHJ) solar cells have attracted constant attention as a cost-efficient power source [1]-[3]. In conventional BHJ solar cells, poly(3-hexylthiophene) (P3HT) as electron donor and [6,6]-phenyl-C61 butyric acidmethylester (PCBM) as electron acceptor blend layer is sand-wiched between a transparent anode and a low work-function metal cathode such as $\mathrm{Ca} / \mathrm{AlorLiF} / \mathrm{Al}$. Water-soluble poly (3,4-ethylenedioxythiophene): poly(styrene-sulfonate) (PEDOT: PSS) has been widely used as an appropriate hole transport layer (HTL) for more efficient hole collection via alignment of work functions of P3HT and transparent ITO anode as well as improvement of contact between active layer and transparent anode by minimizing the detrimental effects of ITO roughness [4].

Graphene may become the new electron conductivity material in place of silicon in the future. Graphene ex- 
hibits a considerable number of new and sometimes mysterious optical and electronic effects that have not been observed in other materials, such as zero-band-gap semi-conductivity with a high carrier mobility, high optical transparency and high tensile strength [5]. Various chemical synthetic methods are used to obtain graphene for basic studies and industrial applications [6]. Additionally, derivatives of graphene, such as graphene oxide and reduced graphene oxide, are being widely investigated from the point of view of primary and practical applications [7] [8]. Polymer solar cells that contain graphene are investigated in three aspects: 1) as the additives to the donor or donor-acceptor material in the BHJ organic photovoltaic cells, 2) as a transparent conductive electrode (anode or cathode) and 3) as a separate layer for organic photovoltaic cells. Recently, grapheme decorated with various inorganic nanoparticles, such as $\mathrm{Pt}, \mathrm{Au}, \mathrm{Ag}, \mathrm{CdS}, \mathrm{TiO}_{2}$ and $\mathrm{ZnO}$ [9] [10], among which $\mathrm{Ag}$ nanocomposites are good candidates for electronics, optics, electrochemistry and catalyst [11] [12]. Graphene/Ag nanoparticle has been proved to be a promising material due to its potential applications in many fields. In this paper, we investigated the effect of adding GA gnanoparticle into the active layer on the characteristics of organic solar cell.

\section{Experimental}

\subsection{Materials}

The ITO substrates $\left(15 \mathrm{ohm} / \mathrm{cm}^{2}\right.$ ) were bought from Lumtec Corp. Graphites powder ( 325 mesh) were purchased from Aifa Aesar. Graphite oxide (GO) was produced via a modified Hummer's method [13], using graphite as raw material, $\mathrm{KMnO}_{4}, \mathrm{KClO}_{4}, \mathrm{NaNO}_{3}$ and $98 \% \mathrm{H}_{2} \mathrm{SO}_{4}$ as oxidants. The Graphene/Ag nanoparticles were prepared in one step reaction [14].

\subsection{Preparation of Organic Polymer Cells}

ITO substrates were cleaned with a special detergent followed by ultrasonication in acetone and isopropylalcohol and then kept in an $100^{\circ} \mathrm{C}$ oven for 30 min. Before the preparation of hole transfer layer (HTL), all substrates we retreated with $\mathrm{UV} / \mathrm{O}_{3}$ for $10 \mathrm{~min}$ to increase wettability of ITO surface. First, the device structure, PEDOT:PSS (Baytron PAI 4083) HTL with a thickness of $40 \mathrm{~nm}$ was spin-coated onto the $\mathrm{UV} / \mathrm{O}_{3}$-treated ITO/glass substrates followed by annealing at $120^{\circ} \mathrm{C}$ for $10 \mathrm{~min}$. The active layer material (P3HT:PCBM:Gag = 1:1:0.01 weight ratio) was dissolved in o-dichlorobenze (o-DCB) and placed on a hot-plate at temperature $70^{\circ} \mathrm{C}$, rotation speed $150 \mathrm{rpm}$ for $24 \mathrm{~h}$. Active layers were spin-coated on HTL coated substrate at $500 \mathrm{rpm}$ for $60 \mathrm{~s}$ using o-DCB solution containing a $25 \mathrm{mg} / \mathrm{mL}$ of P3HT(Rieke Metals) and a $25 \mathrm{mg} / \mathrm{Ml}$ of PCBM (Nano-C). Then, to obtain highly ordered active layer, the active layer coated substrates were kept in a glass jar at room temperature to evaporate o-DCB solvent slowly for 2 hinan $\mathrm{N}_{2}$-filled glove box, followed by annealing at $150^{\circ} \mathrm{C}$ for $30 \mathrm{~min}$ inside the glove box. Finally, cathode electrodes composed of $\mathrm{Ca}(50 \mathrm{~nm}) / \mathrm{Al}(90 \mathrm{~nm})$ with an area of $10 \mathrm{~mm}^{2}$ were deposited using athermal evaporator in vacuum with a pressure of $10^{-6}$ Torr. Figure 1 shows the schematic diagram of the solar cell.

\subsection{Characterization}

The surface morphologies were measured by AFM using a Digital instrument NS3a operated in tapping mode with a silicon cantilever. The optical properties of active layer were investigated via. UV-vis spectrophotometer with a Cary 100 conc. Performance of the solar cells were obtained from the current-density-voltage characteris-

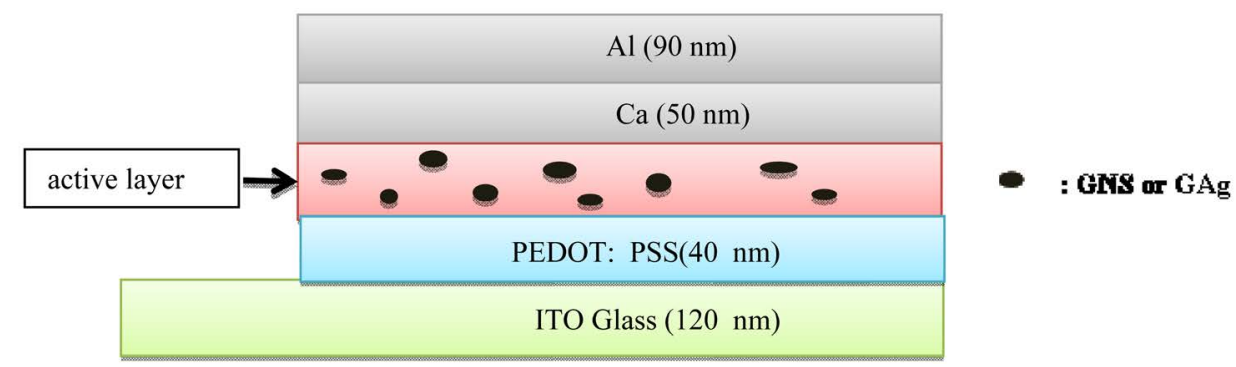

Figure 1. The schematic diagram of solar cell. 
tics under solar simulated irradiation (AM 1.5 G). The solar simulator used for this work was Newport 66,901 instrument.

\section{Results and Discussions}

Figure 2 shows UV-vis absorption spectra of annealed film with different composition of active layer. As the GNS or GAg was added into P3HT: PCBM active layer, absorption peak of P3HT ( $500 \mathrm{~nm})$ increases and broadens, besides showing blue-shift. This tendence depends on the composition of active layer. The active layer with GNS or GAg exhibited higher absorbance than that of active layer without GNS or Gag (0.49). The active layer with GAg-2 exhibited the highest absorbance of 0.68 and an increase of $38 \%$.

The photovoltaic characteristics of the fabricated devices were characterized under simulated A.M 1.5 Gillumination at $100 \mathrm{~mW} / \mathrm{cm}^{2}$. The current-voltage plots of the devices are shown in Figure 3 . The $\mathrm{J}_{s c}$, open-circuit voltage $\left(\mathrm{V}_{\mathrm{oc}}\right)$, fill factor $(\mathrm{FF})$, and PCE values for each set of devices are summarized in Table 1. It can be seen that the P3HT: PCBM-only device exhibits $\mathrm{J}_{s c}$ of $7.12 \mathrm{~mA} / \mathrm{cm}^{2}$ and PCE of $2.23 \%$. The addition of GAg into active layer results in a substantial increase in $\mathrm{J}_{s c}$, and FF, leading to an enhancement in the PCE to $2.49 \%-2.78 \%$. The device which its active layer with GAg-2 had the highest short circuit current density $\left(\mathrm{J}_{s c}\right)$ of $8.56 \mathrm{~mA} / \mathrm{cm}^{2}$, an increase of $20.2 \%$, the highest fill factor (FF) of 0.56 , an increase of $14.3 \%$ and the highest PCE of $2.78 \%$, an increase of $24.7 \%$.This improvement in performance reveals that the electron transport path becomes more well-defined and charge transport properties of active layer was improved by adding graphene or Graphene/Ag nanoparticles.

Figure 4 shows the SPM images of active layer with GAg-2. The root mean square (RMS) roughness of active layer with GAg-2 is $16.6 \mathrm{~nm}$ and smaller than those of active layers with GNS, GAg-1 and GAg-3. Figure 5 shows the SEM images of active layer. The active layer with GNS, GAg-1 and GAg-3 had large particle due to

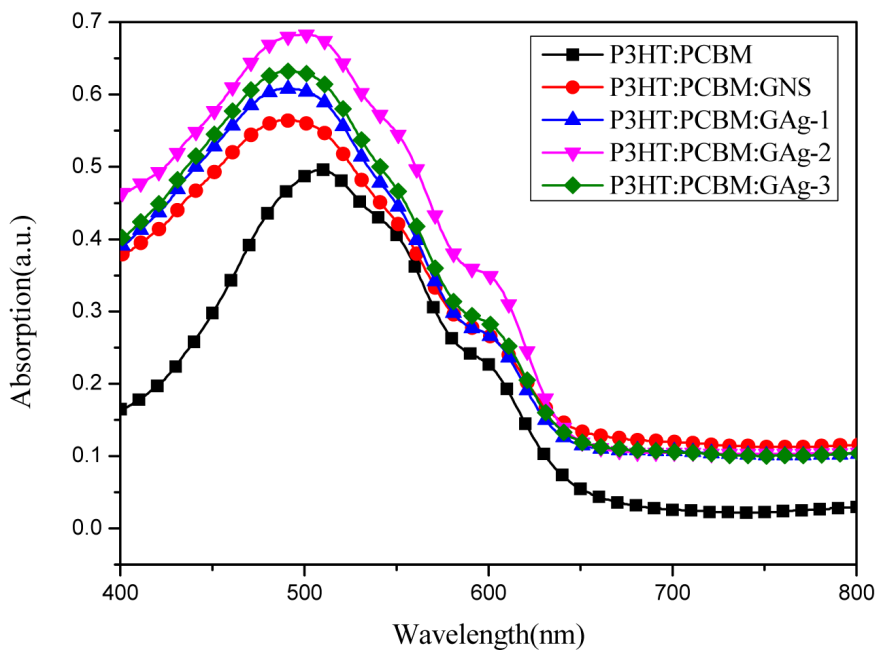

Figure 2. The UV-vis spectra of photovoltaic device with different composition of active layer.

Table 1. Photovoltaic performance of investigated devices.

\begin{tabular}{ccccc}
\hline & Active layer (P3HT: PCBM: Gag = 1:1:0.01) & & \\
\hline Composition & $\mathrm{V}_{\mathrm{oc}}(\mathrm{V})$ & $\mathrm{J}_{\mathrm{sc}}\left(\mathrm{mA} / \mathrm{cm}^{2}\right)$ & $\mathrm{FF}$ & PCE (\%) \\
\hline P3HT:PCBM & 0.63 & 7.12 & 0.49 & 2.23 \\
P3HT:PCBM:GNS & 0.54 & 8.11 & 0.55 & 2.49 \\
P3HT:PCBM:GAg-1 & 0.54 & 8.33 & 0.55 & 2.50 \\
P3HT:PCBM:GAg-2 & 0.56 & 8.56 & 0.56 & 2.78 \\
P3HT:PCBM:GAg-3 & 0.55 & 8.47 & 0.56 & 2.68 \\
\hline
\end{tabular}




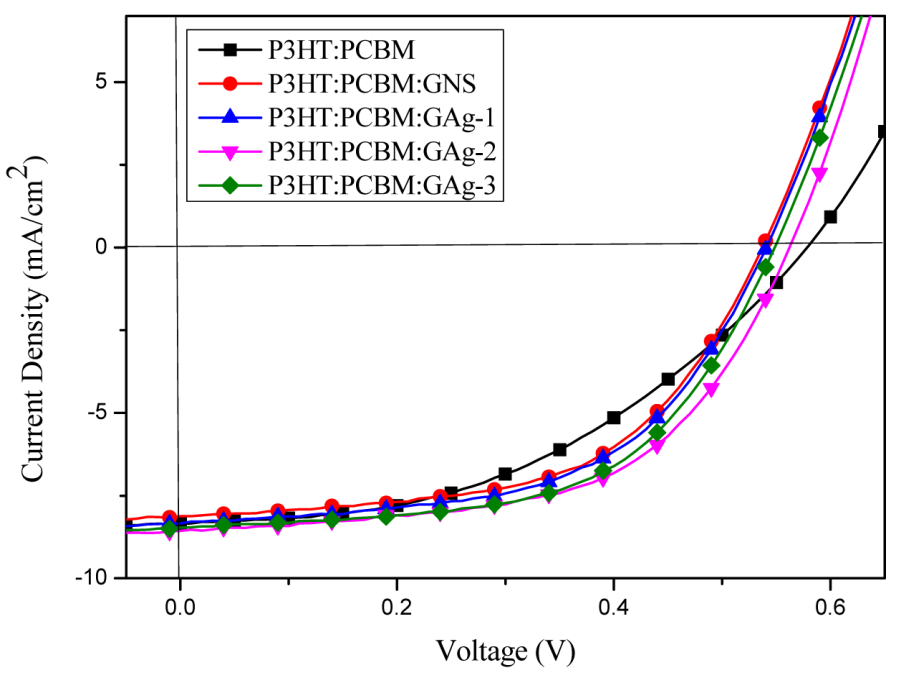

Figure 3. The J-V curves of photovoltaic device with different composition of active layer.
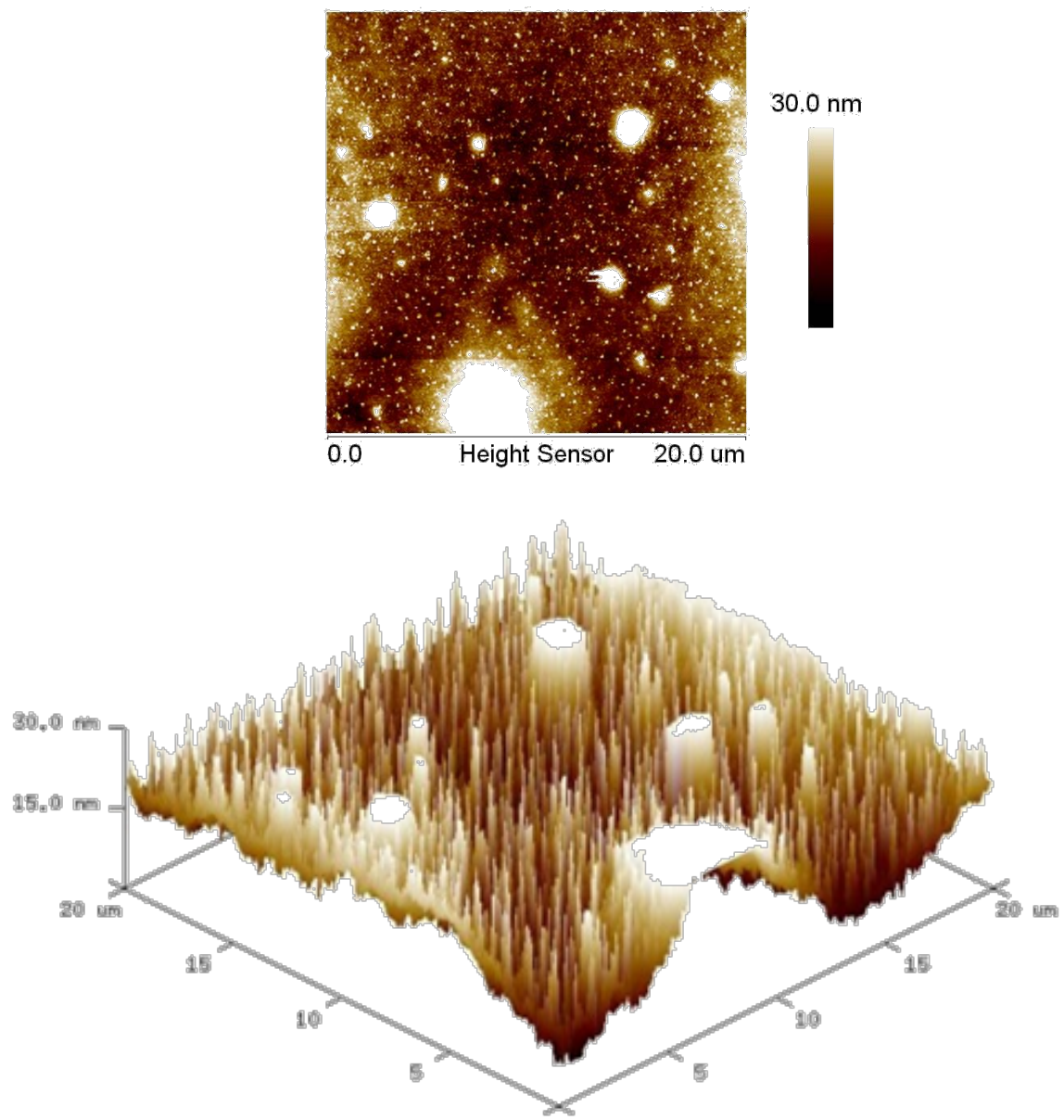

Figure 4. SPM images of active layer with GAg-2.

the aggregation of GAg and the distribution were not uniform. The active layer with GAg-2 exhibited the smallest size and the best distribution among all of the samples. These results induced that the cell with GAg-2 exhibited the highest $\mathrm{J}_{s c}$, FF, and PCE. 

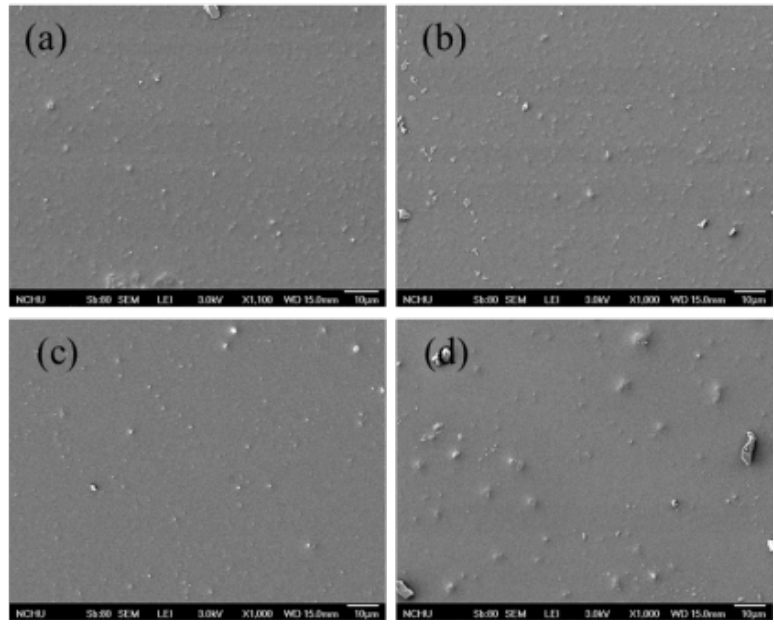

Figure 5. SEM images of active layer with (a) GNS; (b) GAg-1; (c) GAg-2; (d) GAg-3 (×1000).

\section{Summary}

Graphene/Ag nanoparticles (GAg) were fabricated via a facile method and used in polymer solar cell. The GNS or Gag was added into the active layer of polymer solar cell by the 1:1:0.01 weight ratio of P3HT:PCBM:GAg. The $J_{s c}$, FF and PCE of device with GNS or GAg were increased. This improvement in performance is due to an extension of the excitions dissociation area and to faster electron transfer through the graphene or graphene/Ag nanoparticles leading to an enhancement in the PCE. The device with GAg-2 had the highest short circuit current density of $8.56 \mathrm{~mA} / \mathrm{cm}^{2}$, the highest fill factor of 0.56 , and the highest PCE of $2.78 \%$, an increase of $24.7 \%$, compared to the reference cell. These increases appear to be due to the highest absorbance in UV-vis absorption spectrum, the highest uniform distribution of GA gnanoparticles and the smallest roughness of active layer.

\section{Acknowledgements}

The author would like to thank the National Science Council of the Republic of China for financially supporting this research under Contract No. NSC102-2221-E-167-022.

\section{References}

[1] Peet, J., Kim, J.Y., Coates, N.E., Ma, W., Moses, D., Heeger, A.J. and Bazan, G.C. (2007) Efficiency Enhancement in Low-Band Gap Polymer Solar Cells by Processing with Alkanedithiols. Nature Materials, 6, 497-500. http://dx.doi.org/10.1038/nmat1928

[2] Liang, Y.Y., Feng, D., Wu, Y., Tsai, S.-T., Li, G., Ray, C. and Yu, L. (2009) Highly Efficient Solar Cell Polymers Developed via Fine-Tuning of Structural and Electronic Properties. Journal of the American Chemical Society, 131, 7792-7799. http://dx.doi.org/10.1021/ja901545q

[3] Riede, M.K., Sylvester-Hvid, K.O., Glatthaar, M., Keegan, N., Ziegler, T., Zimmermann, B., Niggenmann, M., Liehr, A.W., Willekr, G. and Gombert, A. (2008) High Throughput Testing Pplatform for Organic Solar Cells. Progress in Photovoltaics: Research and Applications, 16, 561-576. http://dx.doi.org/10.1002/pip.836

[4] Meyer, J., Khalandovsky, R., Görrn, P. and Kahn, A. (2011) $\mathrm{MoO}_{3}$ Films Spin-Coated from a Nano Particle Suspension for Efficient Hole-Injection Inorganic Electronics. Advanced Materials, 23, 70-73. http://dx.doi.org/10.1002/adma.201003065

[5] Bisoyi, H.K. and Kumar, S. (2011) Carbon-Based Liquid Crystals: Art and Science. Liq Cryst, 38, 1427-1449. http://dx.doi.org/10.1080/02678292.2011.597882

[6] Allen, M.J., Tung, V.C. and Kaner, R.B. (2010) Honeycomb Carbon: A Review of Graphene. Chem Rev, 110, $132-145$. http://dx.doi.org/10.1021/cr900070d

[7] Dreyer, D.R., Park, S., Bielawski, C.W. and Ruoff, R.S. (2010) The Chemistry of Graphene Oxide. Chem Soc Rev, 39, 228-240. http://dx.doi.org/10.1039/B917103G

[8] Dikin, D.A., Stankovich, S., Zimney, E.J., Piner, R.D., Dommett, G.H.B., Evmenenko, G., Nguyen, S.T. and Ruoff, 
R.S. (2007) Preparation and Characterization of Graphene Oxide Paper. Nature, 448, 457-460. http://dx.doi.org/10.1038/nature06016

[9] Qian, Y., Wang, C.Y. and Le, Z.G. (2011) Decorating Graphene Sheets with Pt Nanoparticle Using Sodium Citrate as Reductant. Applied Surface Science, 257, 10758-10762. http://dx.doi.org/10.1016/j.apsusc.2011.07.093

[10] Yang, Y. and Liu, T.X. (2011) Fabrication and Characterization of Graphene Oxide/Zinc Oxide Nanorods Hybrid. Applied Surface Science, 257, 8950-8954. http://dx.doi.org/10.1016/j.apsusc.2011.05.070

[11] Hranisavljevic, J., Dimitrijevic, N.M., Wurtz, G.A. and Wiederrecht, G.P. (2002) Photoinduced Charge Separation Reactions of J-Aggregates Coated on Silver Nanoparticles. Journal of the American Chemical Society, 124, 4536-4537. http://dx.doi.org/10.1021/ja012263e

[12] Ou, C.F. and Chen, S.Y. (2014) The Effect of Graphene/Ag Nanoparticles Layer on the Performances of Organic Solar Cell. Advanced Materials Research, 953-954, 1067-1071. http://dx.doi.org/10.4028/www.scientific.net/AMR.953-954.1067

[13] Wang, H.L., Robinson, J.T., Li, X.L. and Dai, H.J. (2009) Solvothermal Reduction of Chemically Exfoliated Graphene Sheets. Journal of the American Chemical Society, 131, 9910-9911. http://dx.doi.org/10.1021/ja904251p

[14] Yuan, W.H., Gu, Y.J. and Li, L. (2012) Green Synthesis of Graphene/Ag Nanocomposites. Applied Surface Science, 261, 753-758. http://dx.doi.org/10.1016/j.apsusc.2012.08.094 